\title{
EFEK MEDIASI WORK ENGAGEMENT DALAM PENGARUH JOB \\ CHARACTERISTIC DAN PERCEIVED ORGANIZATIONAL SUPPORT TERHADAP EMPLOYEE PERFORMANCE DI BIDANG IT PADA PERUSAHAAN STARTUP
}

\author{
Sulin \\ Program Studi Magister Manajemen Universitas Tarumanagara \\ sulin.cheuw@yahoo.com \\ Yanuar \\ Program Studi Magister Manajemen Universitas Tarumanagara
}

\begin{abstract}
This research aims to analyze the effect between job characteristic, perceived organizational support, work engagement, and employee performance focusing in IT startup company in Indonesia. Work engagement has been theorized and proven as a mediator between its antecedents to employee performance. But very little research has been focusing on IT sector. Data are collected through questionnaire aiming at employee working in IT sector of various startup companies in Indonesia. Total sample used in this research is 389. Data analysis is conducted with Structural Equation Modelling (SEM) using AMOS software. The result of this research shows that job characteristic is significant at level 0,05 to work engagement. It is also applied to perceived organizational support with 0,05 significant level to work engagement. While their direct effects to employee performance is not significant, by the mediation of work engagement both job characteristic and perceived organizational support is significant to employee performance. This research confirms that in IT sector of startup companies in Indonesia, the effect between job characteristic and perceived organizational support to employee performance are fully mediated by work engagement.
\end{abstract}

Keywords : Job Characteristic, Perceived Organizational Support, Work Engagement, Employee Performance.

\section{PENDAHULUAN}

Di Indonesia belakangan ini sedang maraknya dengan kemunculan perusahaan-perusahaan baru atau startup terutama di bidang teknologi informasi. Berdasarkan data startupranking dalam laporan techinasia, Indonesia termasuk peringkat 4 di dunia setelah US, India, dan Inggris. Menurut startupranking.com, perusahaan yang termasuk dalam kategori startup yaitu: (1) berdiri di bawah 10 tahun, (2) belum diakuisisi, (3) belum go public, dan (4) berkaitan erat dengan teknologi. Walaupun banyak perusahaan yang bermunculan, banyak juga perusahaan yang tutup sebelum mencapai 10 tahun. Tercatat bahwa pada Q2 2017 terjadi penurunan jumlah perusahaan startup sebesar $20 \%$ di Indonesia. Sifat dari startup yang cenderung dimulai dengan tim kecil dan dana yang tidak besar serta harus bergerak cepat untuk mendapatkan kepercayaan investor dan mempertahankan diri dari persaingan tentunya membutuhkan sumber daya manusia yang kompeten, sedangkan jumlah tenaga kerja di bidang IT di Indonesia masih kurang, baik dari segi kualitas dan kuantitas. Dalam hal ini sumber daya manusia yang memiliki kemampuan tersebut adalah aset yang sangat berharga bagi perusahaan. Penggerak utama dari perusahaan adalah manusia, dimana setiap manusia memiliki keunikannya masing-masing dengan segala pola pikir dan kemampuannya. Adalah menjadi tugas bagi organisasi untuk dapat mengelola sumber daya yang ada semaksimal mungkin dengan berusaha meningkatkan kinerja karyawannya. Kinerja karyawan sendiri dapat diartikan sebagai tingkat pencapaian karyawan atas pekerjaan yang dilakukannya 
(Simamora, 2004). Semakin tinggi tingkat pencapaian karyawan mengenai pekerjaannya akan berdampak pada semakin baik pula hasil pekerjaannya.

Adapun istilah engagement menyatakan tingkat sampai sejauh apa seorang karyawan mau menggunakan kemampuan dan waktu serta segala sumber daya lainnya dalam pekerjaannya (Kahn, 1990). Karyawan yang engaged terhadap perusahaannya diikuti dengan peningkatan kinerja dan memberikan usaha lebih untuk mencapai tujuan perusahaan (Robinson, Perryman, \& Hayday, 2004).

Beberapa penelitian menyatakan bahwa work engagement memediasi berbagai variabel untuk menghasilkan peningkatan kinerja karyawan. Menurut Saks (2006), employee engagement memiliki efek mediasi atas variabel transformasional leadership, job characteristic, perceived organizational support, rewards and recognition, procedural justice, dan distributive justice terhadap kepuasan kerja, komitmen organisasi, keinginan berhenti, serta kinerja karyawan. Penelitian ini diperkuat oleh Shantz, Alfes, Truss, \& Soane (2013) yang menyatakan bahwa hubungan job characteristic dan kinerja karyawan dimediasi oleh work engagement.

Berdasarkan latar belakang di atas, tujuan penelitian ini yakni untuk:

1. Mengetahui pengaruh job characteristic terhadap work engagement.

2. Mengetahui pengaruh perceived organizational support terhadap work engagement.

3. Mengetahui pengaruh work engagement terhadap employee performance.

4. Mengetahui pengaruh job characteristic dan perceived organizational support terhadap employee performance dengan mediasi work engagement.

\section{TINJAUAN PUSTAKA}

\section{Teori Employee Performance}

Kinerja karyawan merupakan tingkat pencapaian berdasarkan hasil aktivitas kerja yang dilakukan dalam suatu periode tertentu (Gomes, 1995; Simamora, 2004). Borman \& Motowidlo (1997) menyatakan adanya dua dimensi dari kinerja, yaitu task performance dan contextual performance. Task Performance adalah keefektifan seorang karyawan dalam melakukan aktivitas yang berkontribusi untuk organisasi baik secara langsung atau tidak langsung dengan menyediakan bahan atau bantuan. Contextual Performance adalah aktivitas yang memberikan kontribusi terhadap efektivitas organisasi dengan membentuk konteks sosial dan psikologis yang mengkatalisasi proses dan aktivitas kerja. Contextual performance meliputi dengan sukarela membantu mengerjakan tugas yang bukan bagian dari deskripsi pekerjaan serta membantu dan berkooperasi dengan rekan kerja untuk menyelesaikan suatu pekerjaan.

\section{Teori Work Engagement}

Keterikatan kerja merupakan kondisi pikiran yang positif, dimana seseorang akan menginvestasikan seluruh kemampuannya dalam pekerjaannya dengan semangat, dedikasi, dan penyerapan baik secara fisik, kognitif, maupun emosional (Christian et al., 2011; Schaufeli et al., 2002; Kahn, 1990). Kahn (1990) menyatakan bahwa ada tiga kondisi psikologis yang berhubungan degnan terbentuknya keterikatan di tempat kerja, yaitu makna, keamanan, serta kesediaan.

Schaufeli et al. (2002) membagi dimensi keterikatan kerja ke dalam 3 dimensi: (1) vigor (semangat), merupakan tingkat energi seseorang dalam melakukan pekerjaannya; (2) dedication (dedikasi), yaitu tingkat antusiasme, inspirasi, dan kebanggaan karyawan; dan (3) absorption (absorpsi), yaitu konsentrasi pegawai dalam pekerjaannya. 


\section{Teori Job Characteristic}

Menurut Ivancevich dan Donnely (1980), job characteristic merupakan isi pekerjaan yang dirasakan oleh karyawan sebagai pemegang pekerjaan. Hackman \& Oldham (1976) dalam jurnalnya mengutip Turner \& Lawrence yang menyatakan bahwa individu akan termotivasi dari dalam untuk bekerja dengan baik ketika mereka merasa bahwa pekerjaan mereka memiliki makna (meaningfulness), mereka merasakan tanggung jawab personal terhadap hasil pekerjaan mereka (responsibility), dan mereka mendapatkan pengetahuan dari hasil pekerjaan tersebut secara berkala dan jelas (knowledge of result). Teori job characteristic yang dikembangkan oleh Hackman \& Oldham (1976) menyatakan ada lima objektif yang mempengaruhi hal tersebut, yaitu task variety, task identity, task significance, autonomy, dan feedback.

\section{Teori Perceived Organizational Support}

Perceived Organizational Support (POS) menurut Eisenberger, R. and Huntington (1986) merupakan suatu persepsi karyawan mengenai sejauh mana organisasi menghargai kontribusi karyawan dan peduli atas kesejahteraan karyawan. Ketika karyawan merasa bahwa dukungan organisasi tinggi, maka karyawan akan meleburkan keanggotaan organisasi ke dalam identitas diri mereka dan berusaha mengembangkan pengaruh dan persepsi yang positif terhadap organisasi tempat mereka bekerja.

\section{Hubungan antar variabel}

Kahn seperti dikutip dalam Shantz et al. (2013) menyatakan bahwa konteks pekerjaan dapat menciptakan kondisi dimana seseorang secara personal terikat dengan pekerjaan mereka. Karyawan yang memiliki sumber daya untuk memfasilitasi pekerjaan mereka akan lebih rela untuk menginvestasikan energi dan keseluruhan diri mereka dalam peran kerja mereka.

Kahn (1990) menyatakan bahwa salah satu faktor tumbuhnya rasa keterikatan adalah adanya rasa keamanan (psychological safety), dimana seseorang merasa dapat melakukan sesuatu tanpa perasaan takut atau dampak negatif. Saks (2006) dan Rich et al. (2010) dalam penelitiannya menemukan bahwa perceived organizational support memiliki pengaruh terhadap keterikatan kerja karyawan.

Rich et al. (2010) berpendapat bahwa individu yang memiliki keterikatan akan mengerahkan energi fisik, kognitif, dan emosional dalam peran pekerjaan mereka, sehingga akan menghasilkan kinerja yang lebih baik karena karyawan tersebut bekerja dengan intensitas yang lebih besar dan dalam waktu yang lebih lama, mereka akan lebih teliti dan fokus pada tanggung jawab mereka, dan lebih terikat dengan tugas-tugas yang berhubungan dengan peran mereka.

Karakteristik pekerjaan dan persepsi dukungan organisasi diduga mampu menciptakan tingkat keterikatan yang lebih tinggi, sedangkan tingkat keterikatan kerja yang tinggi diduga mampu menghasilkan kinerja karyawan yang lebih baik. Dari hal ini terdapat kemungkinan bahwa keterikatan kerja memiliki peran sebagai mediator dalam hubungan antara anteseden dan dampak keterikatan kerja. Berbagai penelitian sudah dilakukan untuk melihat adanya peran work engagement sebagai mediasi antara job characteristic dan perceived organizational support terhadap kinerja karyawan yang diukur dengan task performance dan contextual performance (Christian et al., 2011; Rich et al., 2010; Shantz et al., 2013).

Berdasarkan pemikiran tersebut, maka dibuat hipotesis sebagai berikut.

H1. Job characteristic berpengaruh positif terhadap work engagement

H2. Perceived Organizational Support berpengaruh positif terhadap work engagement.

H3. Work engagement berpengaruh positif terhadap kinerja karyawan. 
H4. Job characteristic berpengaruh positif terhadap kinerja karyawan dengan mediasi work engagement.

H5. Perceived Organizational Support berpengaruh positif terhadap kinerja karyawan dengan mediasi work engagement.

\section{METODE PENELITIAN}

\section{Populasi dan Sampel}

Penelitian ini bersifat deskriptif karena bertujuan untuk menggambarkan hubungan antar variabel dengan cara mengumpulkan data kemudian menjelaskan dan menginterpretasikannya.

Populasi dalam penelitian ini adalah karyawan dengan profesi IT yang bekerja di perusahaan startup yang berlokasi di Indonesia. Untuk populasi yang tidak diketahui jumlahnya jumlah sampel minimal dapat menggunakan rumus berikut (Lemeshow, 1990).

$$
n=\frac{z_{1-\frac{\alpha}{2}}^{2} * p(1-p)}{d^{2}}=\frac{1,96^{2} * 0,5 * 0,5}{(0,05)^{2}}=384,16
$$

$$
\begin{array}{ll}
\text { Keterangan: } & \mathrm{n} \quad=\text { jumlah sampel } \\
& \left.Z_{1-\alpha / 2}^{2}=\mathrm{Z} \text { score (pada tingkat kepercayaan } 95 \%, \mathrm{Z} \text { score }=1,96\right) \mathrm{p} \\
=\text { estimasi proporsi (jika tidak diketahui, } 0,5) & \\
\mathrm{d} \quad=\text { presisi }(0,05)
\end{array}
$$

Penelitian dilakukan pada bulan Mei 2018 kepada karyawan-karyawan IT yang bekerja di perusahaan startup dengan cara menyebarkan kuesioner secara online. Sebanyak 389 data

\begin{tabular}{|c|c|c|}
\hline Variabel & Dimensi & Indikator \\
\hline \multirow{6}{*}{$\begin{array}{l}\text { Perceived } \\
\text { Organizational } \\
\text { Support } \\
\text { (POS) } \\
\text { (Eisenberger et } \\
\text { al., 2001) }\end{array}$} & \multirow[t]{6}{*}{ - } & POS1: Kebanggaan pada keberhasilan karyawan \\
\hline & & POS2: Kepedulian terhadap kesejahteraan karyawan \\
\hline & & POS3: Penghargaan atas kontribusi karyawan \\
\hline & & POS4: Menghargai nilai dan tujuan karyawan \\
\hline & & POS5: Perhatian terhadap karyawan \\
\hline & & POS6: Bantuan kepada karyawan \\
\hline \multirow{15}{*}{$\begin{array}{l}\text { Job } \\
\text { Characteristic } \\
\text { (JC) } \\
\text { (Morgesson \& } \\
\text { Humphrey, } \\
\text { 2006) }\end{array}$} & \multirow[t]{9}{*}{ Autonomy } & JC1: Kebebasan merencanakan jadwal pekerjaan \\
\hline & & JC2: Kebebasan merencanakan urutan pekerjaan \\
\hline & & JC3: Merencanakan bagaimana melakukan pekerjaan \\
\hline & & JC4: Inisiatif dan penilaian sendiri \\
\hline & & JC5: Kebebasan membuat keputusan \\
\hline & & JC6: Kemandirian dalam pengambilan keputusan \\
\hline & & JC7: Menentukan metode menyelesaikan tugas \\
\hline & & JC8: Mengerjakan tugas secara mandiri dan bebas \\
\hline & & JC9: Menentukan cara mengerjakan pekerjaan \\
\hline & \multirow[t]{4}{*}{ Task Variety } & JC10: Terdiri atas beragam tugas \\
\hline & & JC11: Mengerjakan hal berbeda \\
\hline & & JC12: Membutuhkan beragam ketrampilan \\
\hline & & JC13: Karyawan mengerjakan tugas yang bervariasi \\
\hline & \multirow[t]{2}{*}{$\begin{array}{l}\text { Task } \\
\text { Significance }\end{array}$} & $\begin{array}{l}\text { JC14: Hasil pekerjaan berdampak besar bagi orang } \\
\text { lain }\end{array}$ \\
\hline & & JC15: Bagian penting dari sesuatu yang lebih besar \\
\hline
\end{tabular}
berhasil dikumpulkan.

\section{Definisi Konsep dan Operasional}

Definisi operasional dari variabel-variabel yang dianalisis adalah sebagai berikut

Tabel 1. Operasionalisasi Variabel 


\begin{tabular}{|c|c|c|}
\hline & & JC16: Berdampak besar untuk orang di luar organisasi \\
\hline & & $\begin{array}{l}\text { JC17: Pengerjaan tugas berdampak bagi orang di luar } \\
\text { organisasi }\end{array}$ \\
\hline & \multirow[t]{4}{*}{ Task Identity } & JC18: Terdiri atas satu bagian utuh \\
\hline & & JC19: Dapat dikerjakan dari awal hingga akhir \\
\hline & & JC20: Kesempatan menyelesaikan pekerjaan \\
\hline & & JC21: Dimulai dan diselesaikan oleh satu orang \\
\hline & \multirow{3}{*}{$\begin{array}{l}\text { Feedback } \\
\text { from Job }\end{array}$} & JC22: Informasi efektivitas saat mengerjakan tugas \\
\hline & & JC23: Feedback atas kinerja \\
\hline & & JC24: Informasi atas hasil kerja \\
\hline \multirow{9}{*}{$\begin{array}{l}\text { Work } \\
\text { Engagement } \\
\text { (WE) } \\
\text { (Schaufeli et } \\
\text { al., 2002) }\end{array}$} & \multirow[t]{3}{*}{ Vigor } & WE1: Keinginan bekerja \\
\hline & & WE2: Energi dalam bekerja \\
\hline & & WE3: Semangat dan keyakinan \\
\hline & \multirow[t]{3}{*}{ Dedication } & WE4: Inspirasi \\
\hline & & WE5: Antusiasme \\
\hline & & WE6: Kebanggaan \\
\hline & \multirow[t]{3}{*}{ Absorption } & WE7: Larut dalam pekerjaan \\
\hline & & WE8: Terbawa suasana \\
\hline & & WE9: Senang bekerja keras \\
\hline \multirow{12}{*}{$\begin{array}{l}\text { Employee } \\
\text { Performance } \\
\text { (EP) } \\
\text { (Williams \& } \\
\text { Anderson, } \\
\text { 1991; Borman } \\
\text { \& Motowidlo, } \\
\text { 1997) }\end{array}$} & \multirow{7}{*}{$\begin{array}{l}\text { Task } \\
\text { Performance }\end{array}$} & EP1: Pekerjaan selesai dengan baik \\
\hline & & EP2: Memenuhi tanggung jawab \\
\hline & & EP3: Mengerjakan tugas sesuai yang diminta \\
\hline & & EP4: Memenuhi sasaran pekerjaan \\
\hline & & $\begin{array}{l}\text { EP5: Mengikuti aktivitas yang mempengaruhi } \\
\text { evaluasi kinerja }\end{array}$ \\
\hline & & EP6: Memperhatikan aspek penting pekerjaan \\
\hline & & EP7: Mampu mengerjakan tugas-tugas penting \\
\hline & \multirow{5}{*}{$\begin{array}{l}\text { Contextual } \\
\text { Performance }\end{array}$} & EP8: Mengeluarkan usaha lebih dan antusiasme \\
\hline & & EP9: Mengerjakan tugas di luar pekerjaan \\
\hline & & EP10: Membantu rekan kerja \\
\hline & & EP11: Megikuti aturan dan prosedur organisasi \\
\hline & & EP12: Mendukung dan melindungi organisasi \\
\hline
\end{tabular}

\section{Metode Analisis}

Metode analisis yang digunakan dalam penelitian ini untuk mengolah data primer dari para responden adalah Structural Equation Models (SEM) dengan menggunakan software AMOS untuk mengetahui hubungan antara variabel. Teknik analisis yang digunakan dalam penelitian ini terdiri atas tiga macam (Ferdinand, 2006), yaitu: (1) Confimatory Factor Analysis (CFA) untuk mengkonfirmasikan faktor dalam suatu kelompok variabel, (2) Regression Weights pada SEM untuk melihat efek pengaruh variabel-variabel dalam model, dan (3) Path Analysis untuk melihat adanya pengaruh tidak langsung dalam hubungan kausalitas.

\section{HASIL PENELITIAN}

Tabel 2. Mean, Standard Deviation, dan korelasi antar variabel

\begin{tabular}{llllll}
\hline \hline Variable & Mean & SD & JC & POS & WE \\
\hline JC & 2,920 & 0,794 & & & \\
POS & 3,100 & 0,686 & 0,051 & &
\end{tabular}




\begin{tabular}{llllll}
\hline \hline $\mathbf{W E}$ & 3,058 & 0,720 & $0,399^{* *}$ & $0,482^{* *}$ & \\
$\mathbf{E P}$ & 3,123 & 0,740 & $0,28 * *$ & $0,428 * *$ & $0,689 * *$ \\
\hline \hline
\end{tabular}

Note: $* * p<0,05$

Tabel 2 menunjukkan deskripsi variabel berdasarkan data yang didapatkan. Hubungan JC dan POS tidak signifikan sehingga dikatakan baik, karena keduanya adalah variabel independent. Pada tahap CFA, ditemukan ada dua indikator dengan loading factor di bawah syarat 0,70 (Chin, 1998), yaitu untuk indikator JC21 dan EP7 dengan nilai 0,30 dan 0,48. Kedua indikator ini kemudian dikeluarkan dari analisis.

Hasil uji goodness of fit terhadap structural model cukup memenuhi kriteria model fit (Ferdinand, 2006) dengan nilai RMSEA $=0,032$ (Baik), GFI = 0,876 (Marginal), AGFI $=$ 0,853 (Marginal), CMIN/DF = 1,394 (Baik), TLI = 0,964 (Baik), CFI = 0,966 (Baik).

Hasil uji validitas dan reliabilitas juga memuaskan dengan AVE $>0,5$ untuk setiap variabel, serta Construct Reliability > 0,70. Hasil uji normalitas menunjukkan skewness dan kurtosis yang masih di batas normal, yaitu diantara $\pm 1,96$ pada tingkat $\alpha=0,05$ secara univariate namun secara multivariate tidak normal dengan nilai 2,362. Hasil uji multikolinieritas menunjukkan nilai VIF $<10$ dan toleran $>0,1$ untuk semua variabel sehingga disimpulkan tidak ada multikolinieritas yang terjadi.

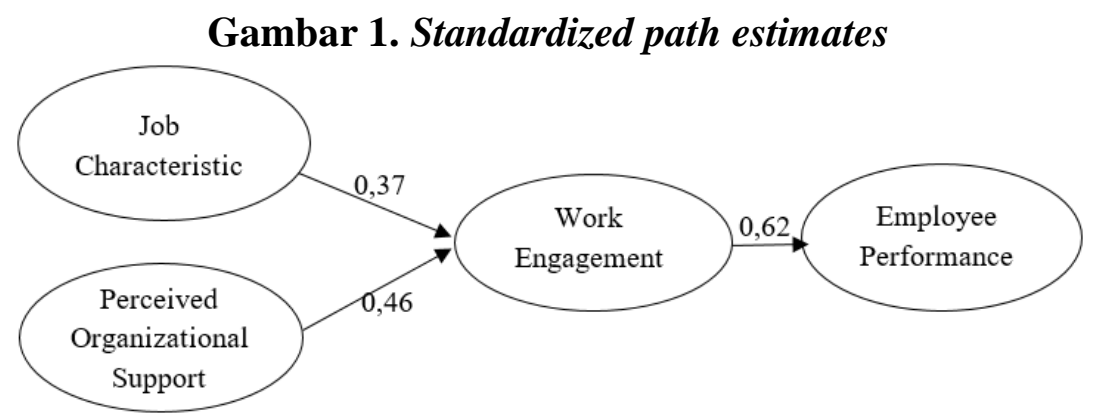

\section{Pengaruh job characteristic terhadap work engagement}

Berdasarkan hasil regression weights, diketahui bahwa JC memiliki efek signifikan terhadap WE $(\mathrm{p}<0,05)$ dengan $\mathrm{CR}=6,186(>2,00)$ dan standardized estimate sebesar 0,37. Dari hasil tersebut, maka hipotesis $\mathrm{H} 1$ mengenai adanya pengaruh job characteristic terhadap work engagement diterima.

\section{Pengaruh perceived organizational support terhadap work engagement}

POS juga memiliki efek yang signifikan $(\mathrm{p}<0,05)$ terhadap WE dengan $\mathrm{CR}=7,301$ $(>2,00)$ dan dapat dikatakan bahwa POS memiliki pengaruh signifikan terhadap WE sebesar 0,46 . Sehingga hipotesis $\mathrm{H} 2$ mengenai adanya pengaruh perceived organizational support terhadap work engagement diterima.

\section{Pengaruh work engagement terhadap employee performance}

WE terhadap EP memiliki efek signifikan ( $<<0,05)$ sebesar 0,62 dan CR =6,591 (> 2,00). Besar efek WE terhadap EP adalah 0,62. Dari hasil tersebut, maka hipotesis H3 mengenai adanya pengaruh work engagement terhadap employee performance diterima.

Pengaruh job characteristic dan perceived organizational support terhadap employee performance dengan mediasi work engagement

Tabel 3. Direct Effects dan Indirect Effects 


\begin{tabular}{lcc}
\hline \multicolumn{1}{c}{ Variabel } & EP & EP melalui WE \\
\hline JC & $0,024(\mathrm{p}=0,724)$ & $0,230^{* *}$ \\
POS & $0,130(\mathrm{p}=0,066)$ & $0,285^{* *}$ \\
\hline \hline
\end{tabular}

Note: $* * p<0,05$

Berdasarkan hasil analisa jalur dan bootstrap untuk melihat signifikansi, terlihat bahwa JC dan POS memiliki efek tidak langsung yang signifikan terhadap EP dengan melalui WE $(\mathrm{p}<0,05)$ dengan efek 0,230 dan 0,285. Sedangkan efek langsung dari JC dan POS terhadap EP tidak signifikan. Sehingga dapat dikatakan bahwa hubungan JC dan POS terhadap EP dimediasi penuh oleh WE. Dari hasil pengujian ini maka hipotesis H4 dan H5 diterima.

\section{PEMBAHASAN}

Job characteristic mempengaruhi employee performance melalui mediasi work engagement sesuai dengan penelitian Shantz et al. (2013) dan Christian et al. (2011). Perancangan pekerjaan yang tepat dapat menciptakan kondisi dimana seseorang secara personal terikat dengan pekerjaan mereka (Kahn dalam Shantz, 2013). Karakteristik dunia IT adalah perkembangannya yang sangat cepat, dan tertinggal dalam hal teknologi dapat mengurangi value dari seorang karyawan IT. Dengan desain pekerjaan yang memungkinkan karyawannya untuk tidak mengerjakan hal yang monoton, melainkan terus mengasah kemampuannya akan menumbuhkan rasa meaningfulness bagi karyawan sehingga karyawan berusaha melakukan yang terbaik dalam pekerjaannya. Kebebasan bagi karyawan untuk bisa bereksperimen dengan cara menyelesaikan suatu masalah akan menumbuhkan rasa memiliki dan tanggung jawab dalam suatu pekerjaan, karena karyawan tersebut memiliki peran dalam mengambil keputusan. Ragam tugas

yang berbeda memicu karyawan untuk mengasah kemampuannya dalam berbagai hal sehingga mereka dapat terus berkembang, dan merasakan makna dari pekerjaan mereka. Kepentingan tugas membuat seseorang merasa bahwa dirinya dibutuhkan dan penting sehingga sebagai balasannya ia akan memberikan yang terbaik bagi pekerjaannya. Scope tugas yang jelas dengan awal dan akhir yang jelas memberikan gambaran bagi karyawan bahwa pekerjaannya memiliki makna dalam pencapaian tujuan organisasi. Dan adanya umpan balik yang jelas dan cukup dapat memberikan kesempatan bagi karyawan untuk berkembang sehingga ia termotivasi untuk menjadi lebih baik lagi.

Penelitian ini juga menemukan bahwa perceived organizational support memiliki pengaruh positif terhadap work engagement serta employee performance melalui mediasi work engagement pada karyawan IT di perusahaan startup.. Hasil ini sesuai dengan penelitian Rich et al. (2010) dan Saks (2006). Karakteristik perusahaan startup yang baru berdiri dan masih berjuang untuk bisa bertahan dapat menimbulkan kekhawatiran bagi karyawan. Karyawan perlu merasa didukung oleh perusahaan, dan dari perasaan didukung tersebut, karyawan akan merasa perlu membalas apa yang telah perusahaan berikan kepada karyawan, dengan cara melakukan pekerjaannya dengan segala kemampuan dan semangat.

Work Engagement memediasi hubungan antara job characteristic dengan kinerja serta hubungan antara perceived organizational support dengan kinerja. Job characteristic memiliki pengaruh positif terhadap employee performance dengan mediasi penuh oleh work engagement. Job characteristic mempengaruhi performa dikarenakan rancangan pekerjaan yang baik akan menumbuhkan rasa keterikatan melalui meaningfulness yang dirasakan karyawan. Perceived organizational support dapat meningkatkan kinerja karyawan dengan adanya keterikatan yang dirasakan oleh karyawan terhadap pekerjaannya yang tumbuh karena rasa keamanan.

\section{KESIMPULAN}


Berdasarkan penelitian yang telah dilakukan dapat diambil beberapa kesimpulan sebagai berikut.

1. Job characteristic memiliki pengaruh positif terhadap work engagement.

2. Perceived organizational support memiliki pengaruh positif terhadap work engagement.

3. Work engagement berpengaruh positif kepada employee performance.

4. Job characteristic memiliki pengaruh pada employee performance karyawan IT di perusahaan startup dengan melalui mediasi work engagement.

5. Perceived organizational support memiliki pengaruh pada employee performance karyawan IT di perusahaan startup dengan melalui mediasi work engagement.

\section{SARAN}

Saran yang dapat diberikan untuk penelitian-penelitian selanjutnya adalah sebagai berikut.

1. Perusahaan startup perlu memperhatikan rancangan pekerjaan, dengan memberikan lebih banyak otonomi bagi karyawannya untuk memilih teknologi yang ingin digunakan, memberikan kesempatan bagi karyawan untuk menyuarakan solusi terhadap suatu permasalahan, dan merencanakan pekerjaan mereka. Selain itu juga dengan memberikan scope tugas yang jelas dan memberikan gambaran akan fungsi dari bagian tugas yang dikerjakan. Variasi pekerjaan serta penggunaan teknologi baru juga perlu dilakukan agar karyawan senantiasa merasa ada perkembangan dan tidak stagnan. Feedback yang membangun perlu diberikan secara berkala, atau dengan membangun suatu sistem dimana setiap karyawan melakukan peer review terhadap rekan kerjanya.

2. Perusahaan startup perlu menunjukkan dukungan dan kepedulian kepada karyawannya, misalnya dengan mengadakan acara kebersamaan, membuat forum terbuka untuk mendengarkan pendapat karyawan, mendengarkan ide-ide karyawan, serta melakukan sesi one on one antara tiap karyawan dengan atasan agar perusahaan dapat mengenal setiap karyawan secara lebih personal dan bertindak terhadap aspirasi setiap karyawannya.

\section{DAFTAR PUSTAKA}

Augusty, Ferdinand. (2006). Metode Penelitian Manajemen: Pedoman Penelitian untuk Skripsi, Tesis dan Disertasi Ilmu Manajemen. Semarang: Universitas Diponegoro.

Borman, W. C., \& Motowidlo, S. J. (1997). Task performance and contextual performance: The meaning for personnel selection research. Human Performance, 10(2), 99-109.

Chin, W. W. (1998). The partial least squares approach for structural equation modeling. In G. A. Marcoulides (Ed.). Mahwah, NJ, US: Lawrence Erlbaum Associates Publishers

Christian, M. S., Garza, A. S., \& Slaughter, J. E. (2011). Work engagement: A quantitiative review and test of its relations with task and contextual performance. Personnel Psychology, 64(1), 89-136.

Eisenberger, R. and Huntington, R. (1986). Perceived Organizational Support. Journal of Applied Psychology, 71(3), 500-507.

Gomes, Faustino C. (1995). Manajemen Sumber Daya Manusia. Yogyakarta : Penerbit Andi.

Hackman, J. R., \& Oldham, G. R. (1976). Motivation through the design of work: test of a theory. Organizational Behavior and Human Performance, 16(2), 250-279.

Ivancevich, John M \& Donnely. (1980). Human Resource Management. Boston: McGraw Hill Irwin.

Kahn, W. A. (1990). Psychological Conditions of Personal Engagement and Disengagement 
at Work. Academy of Management Journal, 33(4), 692-724.

Lemeshow, S., Hosmer, D. W., Klar J., Lwanga S.K. (1990). Adequacy of sample size in health studies. Edisi terjemahan. Yogyakarta: Gadjah Mada University Press.

Morgeson, F. P., \& Humphrey, S. E. (2006). The Work Design Questionnaire (WDQ): Developing and validating a comprehensive measure for assessing job design and the nature of work. Journal of Applied Psychology, 91(6), 1321-1339. Rhoades, L., \& Eisenberger, R. (2002). Perceived organizational support: A review of the literature. Journal of Applied Psychology, 87(4), 698-714.

Rich, B. L., Lepine, J. A., \& Crawford, E. R. (2010). Job engagement: Antecedents and effects on job performance. Academy of Management Journal, 53(3), 617-635.

Robinson, D., Perryman, S., \& Hayday, S. (2004). The Drivers of Employee Engagement. North, 408, 12-15.

Saks, A. (2006). Antecedents and consequences of employee engagement. Journal of Managerial Psychology, 21(7), 600-619.

Schaufeli, W. B., Salanova, M., Gon Alez-ro, V. A., \& Bakker, A. B. (2002). the Measurement of Engagement and Burnout: a Two Sample Confirmatory Factor Analytic Approach. Journal of Happiness Studies, 3, 71-92.

Simamora, Henry. (2004). Manajemen Sumber Daya Manusia. Jakarta: PT Bumi Aksara.

Shantz, A., Alfes, K., Truss, C., \& Soane, E. C. (2013). The role of employee engagement in the relationship between job design and task performance, citizenship and deviant

behaviours. The International Journal of Human Resource Management, 24(13), 2608-2627.

Tech in Asia. (2017). Laporan Kondisi Startup Indonesia Q2 2017. Retrieved July 25, 2017, from Tech in Asia Website. https://id.techinasia.com/laporan-kondisi-startup-indonesiaq2-2017

Williams, L. J., \& Anderson, S. E. (1991). Job Satisfaction and Organizational Commitment as Predictors of Organizational Citizenship and In-Role Behaviors. Journal of Management, 17(3), 601-617 
